\title{
Espaçamentos entre plantas e número de fileiras no canteiro na produção de ervilha
}

\author{
Rosimeire P Gassi; Néstor Antonio Heredia Zárate; Maria do Carmo Vieira; Hellen Elaine Gomes; Elaine \\ Eva O Munarin; Jerusa Rech \\ UFGD-FCA, Dep ${ }^{\text {to }}$ Agronomia, C. Postal 533, 79804-970 Dourados-MS; rpgassi@yahoo.com.br
}

\section{RESUMO}

A ervilha é consumida na forma de grãos verdes ou enlatados, sendo considerada uma opção de produção para atender às novas demandas do mercado, principalmente de produtos supergelados. $\mathrm{O}$ presente trabalho teve por objetivo avaliar o crescimento e a produção da ervilha de grãos verdes 'Luciana $n^{\circ} 50$ ', cultivada sob quatro e cinco fileiras no canteiro e três espaçamentos entre plantas dentro da fileira $(5,0 ; 7,5$ e 10,0 cm), em Dourados-MS. Os tratamentos foram arranjados como fatorial $2 \times 3$, no delineamento experimental de blocos casualizados, com cinco repetições. A altura das plantas não foi influenciada significativamente pela interação número de fileiras no canteiro e espaçamentos entre plantas nem pelos fatores isoladamente, sendo a média de $105,6 \mathrm{~cm}$. Houve interação significativa para as produções de massas frescas e secas da parte aérea, sendo as maiores $\left(10,49 \mathrm{t} \mathrm{ha}^{-1}\right.$ e 2,31 $\left.\mathrm{t} \mathrm{ha}^{-1}\right)$ das plantas cultivadas sob quatro fileiras e 7,5 cm entre plantas e as menores $\left(7,52 \mathrm{t} \mathrm{ha}^{-1} \mathrm{e} 1,98 \mathrm{t} \mathrm{ha}^{-1}\right.$, respectivamente), daquelas sob cinco fileiras e $5,0 \mathrm{~cm}$ entre plantas para massa fresca e quatro fileiras e $10,0 \mathrm{~cm}$ entre plantas para massa seca. A produção de vagem comercial obtida sob quatro fileiras de plantas superou em 1,50 tha ${ }^{-1}$ àquela sob cinco fileiras $\left(5,74 \mathrm{t} \mathrm{ha}^{-1}\right)$ e a obtida sob $10,0 \mathrm{~cm}$ entre plantas foi superior em $2,25 \mathrm{t} \mathrm{ha}^{-1}$ àquela sob 5,0 $\mathrm{cm}\left(5,23 \mathrm{t} \mathrm{ha}^{-1}\right)$. A maior produção de grãos tenros comercializáveis $\left(4,27 \mathrm{tha}^{-1}\right)$ foi com $10 \mathrm{~cm}$ entre plantas, que superou em 1,33 $\mathrm{t} \mathrm{ha}^{-1}$ àquela com $5,0 \mathrm{~cm}$ entre plantas, que foi a menor. Considerando a produtividade de grãos tenros e a estimativa da renda bruta, conclui-se que a cultivar 'Luciana $\mathrm{n}^{\mathrm{0}}$ 50' deve ser cultivada com quatro fileiras de plantas no canteiro e sob $10 \mathrm{~cm}$ entre plantas.

Palavras-chave: Pisum sativum, população de plantas, sementes, renda bruta.

\author{
ABSTRACT \\ Spacing between plants and number of rows per plot on the \\ yield of pea
}

Pea is consumed as green or canned grains, being considered an option of production to take care of the new market demands, mainly of superfrozen products. The growth and the production of green grains pea 'Luciana $\mathrm{N}^{\circ} 50$ ' was evaluated when cultivated in four and five rows per plot and three spacings between plants in rows $(5,0 ; 7,5$ and 10,0 cm), in Dourados, Mato Grosso State, Brazil. Treatments were arranged as a 2 × 3 factorial scheme, in a randomized-blocks experimental design, with five replications. Plant height was not significantly influenced by the interaction between number of rows per plot and spaces between plants, neither by those isolated factors, with an average of $105,6 \mathrm{~cm}$. The interaction was significant for fresh and dried mass of aerial part and the greatest values $\left(10,49 \mathrm{t} \mathrm{ha}^{-1}\right.$ and $2,31 \mathrm{t} \mathrm{ha}^{-1}$ ) were those from plants cultivated in four rows and 7,5 $\mathrm{cm}$ between plants. The smallest values $\left(7,52 \mathrm{t} \mathrm{ha}^{-1}\right.$ and 1,98 $\mathrm{t} \mathrm{ha}^{-1}$, respectively) were those from plants under five rows and spaced $5,0 \mathrm{~cm}$ between plants for fresh mass and four rows and 10,0 cm between plants for dried mass. Yield of commercial pods obtained under four rows of plants was superior in 1,50 $\mathrm{tha}^{-1}$ than those under five rows $\left(5,74 \mathrm{tha}^{-1}\right)$ and the yield obtained in $10 \mathrm{~cm}$ between plants was superior in 2,25 tha-1 than that under 5,0 $\mathrm{cm}\left(5,23 \mathrm{t} \mathrm{ha}^{-1}\right)$. The greatest yield of commercial tender grains $\left(4,27 \mathrm{tha}^{-1}\right)$ was obtainded using spaces of $10 \mathrm{~cm}$ between plants, which was superior in $1,33 \mathrm{t}$ $\mathrm{ha}^{-1}$ than those with 5,0 $\mathrm{cm}$ between plants, which was the smallest one. Considering yield of tender grains and the estimate of gross income, 'Luciana ${ }^{\circ} 50$ ' must be cultivated with four rows of plants per plot and with $10 \mathrm{~cm}$ between plants.

Keywords: Pisum sativum, plant population, seeds, gross income.

(Recebido para publicação em 20 de junho de 2008; aceito em 19 de novembro de 2009)

(Received in June 20, 2008; accepted in November 19, 2009)

$\mathrm{O}$ cultivo de hortaliças é uma das atividades agrícolas com maior custo e risco financeiro, mas em compensação, é a que possibilita a mais alta renda líquida por hectare cultivado. Além disso, está crescendo em ritmo acelerado a participação delas no processo de agroindustrialização, assegurando a definitiva inclusão das principais espécies no rol das mais importantes culturas no Brasil (Vilela \& Macedo, 2000).

O estado de Mato Grosso do Sul ainda não tem tradição no cultivo de hortaliças, praticando principalmente o cultivo de soja ou milho, além da criação de gado de corte. Nos últimos anos, vêm aumentando as áreas de cultivo de hortaliças nos arredores das maiores cidades do estado, o que possibilita a venda do produto diretamente ao consumidor (Heredia Zárate \& Vieira, 2003).

A ervilha (Pisum sativum L., Fabácea) é originária do Oriente Médio, sendo muito apreciada em todo o planeta como legume, sendo consumida como grãos verdes ou enlatados (Pereira,
1989). É considerada excelente alimento, por destacar em sua composição centesimal elevados teores de proteína, vitaminas do complexo $\mathrm{B}$, principalmente tiamina, riboflavina e niacina, além de minerais como cálcio, ferro, fósforo e potássio (Pereira, 1989).

A ervilha-verde é uma opção de produção para atender às novas demandas do mercado, principalmente de produtos supergelados. Diferentemente da ervilha para produção de grãos secos, que são posteriormente reidratados $\mathrm{e}$ 
enlatados, as cultivares de ervilha-verde são próprias para colheita de grãos verdes, visando ao imediato congelamento e/ou enlatamento. O produto pode também ser comercializado na forma de vagens para debulhar ou de grãos debulhados, para consumo in natura (Embrapa, 2008).

No Brasil, as plantas de ervilha são cultivadas em locais de temperaturas amenas ou frias, adaptando-se às condições de outono-inverno, no Centro-Sul (Filgueira, 2000).

Nas condições de Cerrado, várias cultivares estrangeiras ou brasileiras alcançam produtividade e qualidade de grãos muito bons, tanto para a produção de grãos secos, como de grãos verdes (Nascimento et al., 1987, 1994).

Em lavouras comerciais, a produtividade da ervilha tem variado de 3,0 a 6,0 t $\mathrm{ha}^{-1}$ de grãos verdes e experimentalmente, em Brasília, foi alcançado 7,17 t ha ${ }^{-1}$. Em estudos de avaliação de cultivares e linhagens de ervilha realizados em Minas Gerais, as cultivares Jurema, Flávia e Marina foram consideradas mais produtivas que a Mikado que renderam na média de dois ensaios realizados em Uberaba e Viçosa respectivamente 2,13; 2,$11 ; 2,08$ e $1,53 \mathrm{t} \mathrm{ha}^{-1}$ de grãos secos (Vieira et al., 2007).

Moreira et al. (2008), avaliando o comportamento de quatro cultivares de ervilha (Axé, Forró, Frevo e Samba), em Ipameri-GO, para a produção de grãos verdes, não observaram diferenças significativas na produtividade de grãos que alcançou valor médio de 7,01 t ha-1.

Souza (1996) cita que o espaçamento adequado é aquele em que as folhas das plantas devem cobrir toda a superfície entre fileiras na época do máximo florescimento, sem haver entrelaçamentos entre elas. Por isso, as propostas de espaçamento e densidade de plantio para as culturas em geral têm procurado atender às necessidades específicas dos tratos culturais e à melhoria da produtividade. Todavia, alterações em espaçamento e densidade, induzem a uma série de modificações no crescimento e no desenvolvimento das plantas que precisam ser mais bem conhecidas. Desse modo, segundo Almeida \& Sangoi (1996), o manejo da densidade de população de plantas é uma das práticas culturais mais importantes, pois afeta a arquitetura das plantas, altera o crescimento e o desenvolvimento e influencia na produção e partição de fotoassimilados.

Tomm et al. (2002) citam que na produção de grãos de ervilhas no Rio Grande do Sul, o espaçamento de 20 $\mathrm{cm}$ entre fileiras apresentou rendimento de grãos maior que o espaçamento de $40 \mathrm{~cm}$, provavelmente, por facilitar a sustentação mútua das plantas, elevando o fuste e permitindo maior captação de energia solar e maior ventilação, sendo menos favorável ao desenvolvimento de doenças.

Fontes et al. (1979), avaliando três densidades de plantas de ervilha $(25$, 50 e 100 plantas $\mathrm{m}^{-2}$ ), observaram que com 50 e 100 plantas $\mathrm{m}^{-2}$, o rendimento foi respectivamente 12 e $14 \%$ maior que o rendimento de grãos com 25 plantas $\mathrm{m}^{-2}$.

O objetivo deste trabalho foi estudar a ervilha 'Luciana $n^{\circ} 50$ ', cultivada sob quatro e cinco fileiras por canteiro e em três espaçamentos entre plantas dentro das fileiras.

\section{MATERIAL E MÉTODOS}

O experimento foi desenvolvido em campo da UFGD, entre 26/05 e 08/09/2007. O solo é do tipo Latossolo Vermelho distroférrico de textura argilosa, com as seguintes características químicas na camada de 0-20 cm: 4,7 de pH em $\mathrm{CaCl}_{2}$ 30,1 $\mathrm{g} \mathrm{dm}^{-3}$ de M.O.; 21 $\mathrm{mg} \mathrm{dm}{ }^{-3}$ de P, 7,2; 28,0 e 17,0 mmol $_{c}$ $\mathrm{dm}^{-3}$ de $\mathrm{K}, \mathrm{Ca}$ e $\mathrm{Mg}$, respectivamente.

O local do experimento situa-se em latitude de $22^{\circ} 11^{\prime} 43^{\prime}$ 'S, longitude de 5456'08' e altitude de $458 \mathrm{~m}$. O clima, segundo a classificação de köppen, é Mesotérmico úmido, do tipo Cwa, com temperaturas e precipitações anuais variando de $20^{\circ}$ a $24^{\circ} \mathrm{C}$ e de 1250 a 1500 $\mathrm{mm}$, respectivamente.

Foi estudada a ervilha 'Luciana $n^{\circ}$ 50 ', sob quatro e cinco fileiras no canteiro de 1,0 m de largura e três espaçamentos entre plantas $(5,0 ; 7,5$ e 10,0 cm) na fileira, correspondendo às populações de 264.000; 330.000; 351.912; 439.890; 528.000 e 660.000 plantas ha ${ }^{-1}$.

Os tratamentos foram arranjados em esquema fatorial 2 (número de fileiras no canteiro) x 3 (espaçamento entre plantas), no delineamento experimental de blocos casualizados, com cinco repetições. As parcelas tinham área total de $3,30 \mathrm{~m}^{2}(1,50 \mathrm{~m}$ de largura por 2,20 m de comprimento) e área útil de $2,20 \mathrm{~m}^{2}$ (canteiro de 1,0 m de largura e 2,20 m de comprimento).

Para a implantação do experimento, o terreno foi preparado com aração, gradagem e levantamento dos canteiros com rotoencanteirador. Para a semeadura, foram abertos sulcos de aproximadamente 0,05 $\mathrm{m}$ de largura $\mathrm{x}$ 0,05 $\mathrm{m}$ de profundidade, onde foram colocadas as sementes e posteriormente cobertas com a terra movimentada do sulco.

Os tratos culturais consistiram em irrigações, utilizando o sistema de aspersão, com turnos de rega a cada dois dias e capinas, com enxada entre os canteiros e manualmente dentro dos canteiros. Não houve infestações de pragas ou infecções por fitopatógenos.

A colheita foi realizada aos 105 dias após a semeadura, quando as plantas apresentavam mais de $50 \%$ da senescência da parte foliar, época em que foram avaliadas as alturas das plantas, as produções de massas fresca e seca da parte aérea, número de vagens e de grãos, comercializáveis e não-comercializáveis. Também, foram medidos comprimento, largura e espessura das vagens comercializáveis e não-comercializáveis.

Os dados obtidos foram submetidos à análise de variância e quando se verificou significância pelo teste F, aplicou-se o teste de Tukey, a 5\% de probabilidade. Como formas de validação do trabalho foram realizadas estimativas da renda bruta, considerando as produções de massa fresca de grãos comercializáveis e o preço pago ao agricultor de DouradosMS, por cada quilograma de grão verde de ervilha.

\section{RESULTADOS E DISCUSSÃO}

As produções de massas frescas e secas da parte aérea foram influenciadas significativamente pela interação número de fileiras no canteiro e espaçamento entre plantas.

O melhor tratamento foi obtido com 
Tabela 1. Altura média de plantas, produção de massa fresca de vagens e de grãos tenros, comercializáveis e não-comercializáveis, da ervilha 'Luciana $n^{\circ} 50^{\prime}$ ', cultivada sob quatro e cinco fileiras no canteiro e três espaçamentos entre plantas (average plant height, yield of fresh mass of pods and tender grains, commercial and non commercial, of 'Luciana $\mathrm{n}^{\circ}$ 50' pea, cultivated under four and five rows per plot and three spacing between plants). Dourados, UFGD, 2007.

\begin{tabular}{|c|c|c|c|c|c|}
\hline \multirow{3}{*}{ Fileiras no canteiro } & \multirow{3}{*}{$\begin{array}{l}\text { Altura da planta } \\
\qquad(\mathrm{cm})\end{array}$} & \multicolumn{4}{|c|}{ Produção de massa fresca $\left(\mathrm{t} \mathrm{ha}^{-1}\right)$} \\
\hline & & \multicolumn{2}{|c|}{ Vagens } & \multicolumn{2}{|c|}{ Grãos tenros } \\
\hline & & Comercial & Não-comercial & Comercial & Não-comercial \\
\hline 4 & $103,86 \mathrm{a}$ & $7,24 \mathrm{a}$ & $0,56 \mathrm{~b}$ & $3,82 \mathrm{a} *$ & $0,45 \mathrm{~b}$ \\
\hline 5 & $107,45 \mathrm{a}$ & $5,74 \mathrm{~b}$ & $0,94 \mathrm{a}$ & $3,39 \mathrm{a}$ & $0,79 \mathrm{a}$ \\
\hline \multicolumn{6}{|c|}{ Espaçamentos entre plantas $(\mathrm{cm})$} \\
\hline 5,0 & $96,69 \mathrm{a}$ & $5,23 \mathrm{~b}$ & $1,04 \mathrm{a}$ & $2,94 \mathrm{~b}$ & $0,88 \mathrm{a}$ \\
\hline 7,5 & $110,84 \mathrm{a}$ & $6,78 \mathrm{a}$ & $0,77 \mathrm{a}$ & $3,61 \mathrm{a}$ & $0,63 \mathrm{a}$ \\
\hline 10,0 & $109,34 \mathrm{a}$ & $7,48 \mathrm{a}$ & $0,43 \mathrm{~b}$ & $4,27 \mathrm{a}$ & $0,36 \mathrm{~b}$ \\
\hline $\mathrm{CV}(\%)$ & 5,48 & 17,23 & 42,16 & 16,39 & 36,06 \\
\hline
\end{tabular}

*Médias seguidas de mesma letra, na coluna não diferem entre si, pelo teste de Tukey, a 5\% de probabilidade (means followed by same letter in column do not differ by Tukey test at 5\% probability, $\mathrm{p}>0.05$ ).

plantas cultivadas sob quatro fileiras e $7,5 \mathrm{~cm}$ entre plantas com produção de $10,49 \mathrm{tha}^{-1}$ de massa fresca e 2,31 $\mathrm{tha}^{-1}$ de massa seca e as menores produtividades foram obtidas com cinco fileiras e 5,0 $\mathrm{cm}$ entre plantas para massa fresca $\left(7,52 \mathrm{tha}^{-1}\right)$ e quatro fileiras e $10,0 \mathrm{~cm}$ entre plantas para massa seca $(1,98 \mathrm{t}$ ha-1).

Segundo Arismendi (1975), citado por Graciano (2005), o espaçamento entre fileiras e entre plantas exerce grande influência no comportamento das plantas, afetando a arquitetura, desenvolvimento, peso, qualidade e, dentre outras características, a mais importante que é a produção.

Tabela 2. Comprimento (C), largura (L) e espessura (E) de vagem comercializável e nãocomercializável da ervilha 'Luciana $\mathrm{n}^{\circ} 50$ ', cultivada sob quatro e cinco fileiras no canteiro e três espaçamentos entre plantas (length (C), width (L) and thickness (E) of commercial and non commercial pods of 'Luciana $\mathrm{n}^{\circ} 50$ ' pea, cultivated under four and five rows per plot and three spacing between plants). Dourados, UFGD, 2007.

\begin{tabular}{|c|c|c|c|c|c|c|}
\hline \multirow{2}{*}{ Fileiras no canteiro } & \multicolumn{3}{|c|}{ Vagem comercial (mm) } & \multicolumn{3}{|c|}{ Vagem Não-comercial } \\
\hline & $\mathbf{C}$ & $\mathbf{L}$ & $\mathbf{E}$ & $\mathbf{C}$ & $\mathbf{L}$ & $\mathbf{E}$ \\
\hline 4 & $67,36 \mathrm{a}$ & $14,73 \mathrm{a}$ & 9,42 & $62,39 \mathrm{a}$ & $11,89 \mathrm{~b}$ & $6,14 \mathrm{a}$ \\
\hline 5 & $68,99 \mathrm{a}$ & $15,13 \mathrm{a}$ & $10,27 \mathrm{a}$ & $66,21 \mathrm{a}$ & $13,44 \mathrm{a}$ & $6,92 \mathrm{a}$ \\
\hline
\end{tabular}

Espaçamento entre

plantas (cm)

\begin{tabular}{lcccccc}
\hline 5 & $68,00 \mathrm{a}$ & $14,50 \mathrm{a}$ & $11,03 \mathrm{a}$ & $64,92 \mathrm{a}$ & $13,01 \mathrm{a}$ & $6,74 \mathrm{a}$ \\
7,5 & $70,22 \mathrm{a}$ & $14,18 \mathrm{a}$ & $9,40 \mathrm{a}$ & $59,99 \mathrm{a}$ & $12,08 \mathrm{a}$ & $6,02 \mathrm{a}$ \\
10 & $66,31 \mathrm{a}$ & $16,12 \mathrm{a}$ & $9,09 \mathrm{a}$ & $67,99 \mathrm{a}$ & $12,90 \mathrm{a}$ & $6,83 \mathrm{a}$ \\
\hline $\mathrm{CV}(\%)$ & 7,61 & 14,44 & 23,24 & 17,16 & 15,66 & 17,46 \\
\hline
\end{tabular}

Médias na coluna, seguidas por letras diferentes, diferem estatisticamente entre si, pelo teste $\mathrm{F}$, a $5 \%$ de probabilidade (means followed by different letters in the column differ significantly by Tukey test at $5 \%$ probability, $\mathrm{p}<0.05)$.
Ao se relacionar o número de fileiras, com a produção de vagem comercial observou-se que as plantas sob quatro fileiras superaram em $1,50 \mathrm{t} \mathrm{ha}^{-1}$ à sob cinco fileiras $\left(5,74 \mathrm{t} \mathrm{ha}^{-1}\right)$.

Quando se relacionou com os espaçamentos, o espaçamento de $10,0 \mathrm{~cm}$ entre plantas $\left(7,48 \mathrm{tha}^{-1}\right)$ foi superior em $2,25 \mathrm{tha}^{-1}$ à com $5,0 \mathrm{~cm}$, que foi a menor. Esses resultados podem ser explicados por Heredia Zárate (1995) quando cita que a competição por fatores essenciais de crescimento como luz, água, nutrientes podem reduzir a capacidade produtiva da planta. Por outro lado, Johnson et al. (1998) observaram uma elevação do rendimento de grãos de milho com a redução do espaçamento entre linhas, e atribuíram esse incremento à melhor eficiência na intercepção de radiação.

Nas produções de vagens e de grãos tenros não-comercializáveis foi observada tendência inversa ao registrado para a produção de vagens comerciais, ou seja, as maiores produções foram com cinco fileiras e com $5,0 \mathrm{~cm}$ entre plantas, respectivamente (Tabela 1).

Resultados diferentes foram observados por Souza et al. (2002) em feijoeiro (Phaseolus vulgaris L., Fabácea), que observaram que mesmo aumentando a população de plantas de (100 a $400 \mathrm{mil}$ plantas $\left.\mathrm{ha}^{-1}\right)$ o rendimento de grãos se manteve no mesmo patamar, evidenciando certa plasticidade da planta.

Tomm et al. (2002), estudando as cultivares de ervilha para produção de 
Tabela 3. Estimativa da renda bruta de grãos comercializáveis da ervilha 'Luciana $\mathrm{n}^{\circ} 50$ ', cultivada sob quatro e cinco fileiras no canteiro e três espaçamentos entre plantas (estimated gross income of commercial grains of pea 'Luciana $\mathrm{n}^{\circ} 50$ ', cultivated under four and five rows per plot and three spacing between plants). Dourados, UFGD, 2007.

\begin{tabular}{cccc}
\hline $\begin{array}{c}\text { Número de } \\
\text { fileiras }\end{array}$ & $\begin{array}{c}\text { Espaçamento entre } \\
\text { plantas (cm) }\end{array}$ & $\begin{array}{c}\text { Produção } \\
\left(\mathbf{k g ~ h a}^{-1}\right)\end{array}$ & $\begin{array}{c}\text { Renda bruta }^{\mathbf{1}} \\
\text { (R\$) }\end{array}$ \\
\hline \multirow{3}{*}{4} & 5 & $3.140,00$ & $15.700,00$ \\
& 7,5 & $3.920,00$ & $19.600,00$ \\
& 10 & $4.390,00$ & $21.950,00$ \\
\hline & 5 & $2.730,00$ & $13.650,00$ \\
& 7,5 & $3.300,00$ & $16.500,00$ \\
& 10 & $4.150,00$ & $20.750,00$ \\
\hline
\end{tabular}

${ }^{1} \mathrm{R} \$ 5,00 \mathrm{~kg}^{-1}$ de grãos tenros; Preço pago ao produtor de ervilha de grão, em DouradosMS, em outubro de 2007 (R\$ $5.00 \mathrm{~kg}-1$ of tender grains; Price paid to producers of peas, in Dourados-MS, in October 2007).

grãos secos Maria e Alfetta, sob cinco densidades $(30,60,90,120$ e 150 plantas $\mathrm{m}^{-2}$ ) e dois espaçamentos entre fileiras (20 e $40 \mathrm{~cm}$ ), em 2000 e 2001, observaram que o efeito dos espaçamentos e das cultivares foi significativo e não foram observadas interações entre os três fatores (densidades, espaçamentos e cultivares).

O rendimento de grãos não diferiu entre as densidades de 150 a 30 plantas $\mathrm{m}^{-2}$, em ambos os anos, indicando que é possível reduzir em até $75 \%$ a densidade de semeadura, em relação ao anteriormente preconizado (120 plantas $\mathrm{m}^{-2}$ ).

O comprimento, a largura e a espessura das vagens comercializáveis e não-comercializáveis não foram influenciados significativamente pelos fatores testados, exceto a largura das vagens não-comercializáveis que foi maior quando provenientes de plantas cultivadas sob cinco fileiras (Tabela 2).

$\mathrm{O}$ valor médio de comprimento $(68,18 \mathrm{~mm})$ obtido neste experimento está dentro da faixa de valores ( 60 a 75 $\mathrm{mm}$ ) citados pela Embrapa (2008) para várias cultivares.

Pela estimativa da renda bruta, observa-se que o cultivo sob quatro fileiras e $10 \mathrm{~cm}$ entre plantas superou em R \$ 8.300,00 (+60,8\%) à renda bruta obtida com cinco fileiras e $5 \mathrm{~cm}$ entre plantas, tratamento este com a menor produção (Tabela 3). Esses resultados estão coerentes com a citação de Terra et al. (2006) quando destacam a neces- sidade de se estudar economicamente a aplicabilidade de algumas técnicas agrícolas.

Considerando a produtividade de grãos tenros e a estimativa da renda bruta, concluiu-se que a cultivar 'Luciana $n^{\circ} 50^{\prime}$ deve ser cultivada sob quatro fileiras de plantas no canteiro e com 10 $\mathrm{cm}$ entre plantas, quando é obtida maior renda bruta.

\section{AGRADECIMENTOS}

Ao CNPq pelas bolsas e pelo apoio financeiro.

\section{REFERÊNCIAS}

ALMEIDA ML; SANGOI L. 1996. Aumento da densidade de plantas de milho para regiões de curta estação estival de crescimento. Pesquisa Agropecuária Gaúcha 2: 179-183.

ARISMENDI JG. 1975. Efeito do método de produção de mudas e população no rendimento do repolho (Brassica oleraceae var. capitata). Viçosa: UFV. 50p. (Tese mestrado).

EMPRESA BRASILEIRA DE PESQUISA AGROPECUÁRIA. Centro Nacional de Pesquisa de Hortaliças. Ervilha para produção de grãos verdes. Disponível em www.cnph. embrapa.br/cultivares/ervilha. Acesso em 20/01/2008

FILGUEIRA FAR. 2000. Novo manual de olericultura: agrotecnologia moderna na produção e comercialização de hortaliças. Viçosa: UFV. 402 p.

FONTES RR; GIORDANO LB; CAMPOS TGS; CARRIJO OA. 1979. Adubação e densidade de semeadura na produtividade de sementes de ervilha. Pesquisa Agropecuária Brasileira 14: 323-327.
GRACIANO JD. 2005. Arranjo de plantas e cobertura do solo com cama-de-frango na produção de dois clones de mandioquinhasalsa, em Dourados-MS. Dourados: UFMS. 50p. (Tese doutorado).

HEREDIA ZÁRATE NA. 1995. Produção de cinco clones de inhame cultivados no Pantanal sul-matogrossense. Horticultura Brasileira 13: 38-40.

HEREDIA ZÁRATE NA; VIEIRA MC. 2003. Hortas: conhecimentos básicos. Dourados: UFMS. 57p.

JOHNSON GA; HOVERSTAD TR; GREENWALD RE. 1998. Integrated weed management using narrow corn row spacing, herbicides, and cultivation. Agronomy Journal 90:40-46.

MOREIRA FM; SILVA IA; PEREIRA JA; PEIXOTO N. BUENO THA; FIRMINO WG; JUNIOR JM. 2008. Avaliação de cultivares de ervilha para processamento. Disponível em: $<$ http://200.210.234.180/HORTA/Download/ Biblioteca/46>. Acesso em 3/2/2008.

NASCIMENTO WM; GIORDANO LB; CAMARA FLA; LEITE SLS. 1987. Produção de sementes de ervilhas destinadas à industrialização. Horticultura Brasileira 5: 34-36.

NASCIMENTO WM; GIORDANO LB. 1994. Avaliação de linhagens de ervilha para enlatamento e congelamento. Horticultura Brasileira 12: 181-183.

PEREIRAAS. 1989. Ervilha: Integração Pesquisa/ Iniciativa Privada. Informe Agropecuário 158: 52-64.

SOUZA AB; ANDRADE MJB; MUNIZ, JA; REIS RP. 2002. Populações de plantas e níveis de adubação e calagem para o feijoeiro (Phaseolus vulgaris 1.) em um solo de baixa fertilidade. Ciência e Agrotecnologia 26:8798.

SOUZA LC. 1996. Componentes de produção do cultivar de algodoeiro CNPA-7H em diferentes populações de plantas. Viçosa: UFV. 71p (Tese doutorado).

TERRA ER; HEREDIA ZÁRATE NA; VIEIRA MC; MENDONÇA PSM. 2006. Proposta de cálculo e forma de adubação, com e sem amontoa, para a produção e renda bruta do milho Superdoce 'Aruba'. Acta Scientiarum 28: $75-82$.

TOMM GO; PARABONI LG; DONIDA B. 2002. Espaçamento para produção de grãos secos de ervilha no Rio Grande do Sul. Embrapa trigo. (Circular técnica 8).

VIEIRA FV; PINTO CMF; VIEIRA C. 2007. Ervilha (Pisum sativum L.). In: PAULA JÚNIOR TJ; VENZON M. 101 culturas. Manual de Tecnologias Agrícolas. Belo Horizonte. EPAMIG. 800p.

VIEIRA RF; RESENDE MAV; SANTOS CM. 2000. Épocas de plantio de ervilha em Patos de Minas, Uberaba e Janaúba, Minas Gerais. Ciência e Agrotecnologia 24:74-80.

VILELA NJ; MACEDO MMC. 2000. Fluxo de poder no agronegócio: o caso das hortaliças. Horticultura Brasileira 18: 88-94. 